\title{
Digital politics on Facebook during the Arab Spring in Morocco: Adaptive strategies of satire relative to its political and cultural context
}

\author{
Mohamed Mifdal \\ Chouaib Doukkali University \\ mifdal.m@ucd.ac.ma
}

\begin{abstract}
When the Arab Spring began, a growing number of Moroccan Facebookers flaunted their dissent in the face of the regime and used subversive satire to question its legitimacy or push for more freedoms. However, this expression in the form of satire waned after the situation became settled and the satirists had to adjust their satire to the new political reality. This article explores the adaptive strategies of satire in a repressive context during settled and unsettled periods. By scrutinizing satiric posts on Facebook for over four years, I argue that satire, as critique and resistance, adjusts itself to the context, either by taking advantage of increased political space and freedoms or by resorting to indirection, self-censorship or tactical play with power. In both instances, the satiric performance is bound to stay within consensual cultural and political norms even when it is most subversive as these norms profoundly shape its creation and public reception.
\end{abstract}

Keywords: humour, European, journal.

\section{Introduction}

Satire has shifted to a new position of dominance in media and social networking sites as its ability to speak truth to power has become apparent throughout the world (Gray et al. 2009: 6). Though satire has been heralded worldwide as a "critical interrogator of politicians" (Gray et al. 2009: 4), there is little understanding of the ways satire adjusts itself to precarious or repressive political realities, in terms of its choice of issues and targets, its ability to transgress boundaries, its propensity either to adopt survival stances or challenge dominant power structures. After the outbreak of the Arab Spring, satire has thrived in social networking sites and forms now a key part of the digital political culture. Facebookers have a strong affinity for satire because it enables them to voice their resistance to domination on an everyday basis and to criticize social and political abuses.

Scholars of humour have focused on the study of political satire in its different forms during settled periods in repressive or democratic societies; however, few of them have kept 
track of the changes in the workings of satire before, during and after unstable transitional periods. The aim of this paper is to reassess the workings of satire and its effects in the Moroccan context. The impact of satire is, as I will argue, culture-bound and is dependent for its effect on the culture that shapes the Moroccan mindset and the prevailing power relations. Most political satire in Morocco had been clandestine, indirect or self-censored before 2011; nevertheless, its cumulative effect was bound to emerge in the public sphere, including social media, to take on the form of overt public critique during the unsettled period of the Arab Spring.

\section{Method and contextual determinants}

Given the specificity of the context and content of the object of our research, netnography is the most suitable method of study. Accordingly, the researcher has to fit in as a cultural insider to gain the perspective as a member of the virtual community. In effect, I used my own Facebook account to have access to more than 2000 users' timelines. I studied satirical posts published on these timelines for more than four years (2010-2014). Besides, by tracking the sources of the satirical posts shared by these users, I could identify two main community (media and publishing) pages on Facebook: The screaming of Moroccans and Humor politique (with 143,139, and 363,921 subscribers respectively as of December 2014) and studied all the satirical posts published on them.

However, Facebook is composed of individuals and communities that rarely see each other and whose identities are sometimes anonymous, using screen names. In addition to this selfsimulation, suspicion and fear make users reluctant to respond positively to online interviews or to give opinion about politics in Facebook chatrooms or via e-mail. Compensatory interpretive skills were needed; I had to focus mostly on voluntary responses to the posts I studied, namely the "likes", sharing and comments. To avoid misinformation and misinterpretation, I relied on prolonged engagement, persistent observation and triangulating across sites and sources (observing demonstrations and the banners used and keeping track of their news on media). Nevertheless, the study was mainly focused on the virtual discourses and behaviours of Facebookers, using both textual analysis and critical discourse analysis.

This study relies on downloaded materials from Facebook that have been collected for four years (578 satirical posts) and classified into types according to the satiric mode used. Though the quantitative method was sometimes used, I relied mostly on the qualitative analysis of the comments and behaviours of the users because, though numerical descriptions give an objective perspective, the results can be limited and might even be misleading. However, data was also analyzed quantitatively; a line graph was used to represent the shift of Facebook posts in terms of posts. The proportional change in the satiric modes used over four years was tracked and represented in a table to show how satire adapts itself to surrounding political circumstances and how overstepping political boundaries is framed by the modes used by the satirist. The increase or decrease of the use of certain satiric modes is marked in statistical terms and this gives ample concrete evidence of the trends in the use of satire in its different modes over four years. The interpretation of these statistics is to show how satire changes strategies in terms of targets, boundaries and modes in response to existing political realities and to whether the situation is stable or unstable.

The method used here relies both on qualitative and quantitative analysis of the collected data. The aim of the research is to identify the conditions under which satire can change its strategies according to existing political realities, and to find evidence of how satire can have a certain impact on these realities, either by maintaining or subverting them. The conclusions are drawn from the analysis of the data quantitatively (graph and table) and qualitatively as 
these conclusions are based on the observation of dozens of posts for each satirical mode or trends. That is, each post analyzed in this paper represents such trends and modes and is thus representative of dozens of similar posts. Data analysis was conducted through typical methodological steps, including the search for indicators related to the core issue of this paper (adaptive strategies), coding, finding coded categories and concepts (blame shifting, scapegoating, etc.). These methodological steps provide standards for the analysis of the Facebook posts and guarantee some objectivity for the conclusions drawn from the analysis.

This paper proceeds as follows: the review of literature will place the problematic issue of the relation of satire to existing political realities in its wider context and then the paper will provide a detailed analysis of the samples with some conclusions drawn and discussed in light of the ongoing political realities and the findings of other researchers.

\section{Literature review and historical context}

By focusing on everyday resistance in its prosaic satiric form, the paper follows a countertradition that has emerged in the Anglo-American culture, established by cultural studies and postmodernism, which stresses the "quotidian and non-formalized aspects of social interaction" (Gardiner 2000: 3). Everyday life is the locus of a persistent resistance that may use satire to voice indignation at social inequalities. Scholars of humour disagree on the nature and scope of the effects of satire on the existing order and on its ability to bring about change in existing power relations. There has been a heated debate on this issue due to the different approaches adopted by scholars. We can classify them in two categories in terms of the research focus of this paper.

Some approaches view humour as a social fact, and an indicator of social tensions and hierarchies. Drawing on Emile Durkheim, Christie Davies views humour as a "social fact" that needs to be explained by other social facts (2011:7) and maintains that "[j] okes are a brief time off from the everyday inhibitions and restrictions that bind the way we speak" (2011: 3). The key explanation of the jokes, he contends, is "always the centre-edge relationships of the jokers and the butt of their jokes" (Davies 1998: 1). This approach to humour refutes any other explanations that view humour as an expression of conflict and hostility or as a strategy of resistance. He explains that "[j] okes are like pea-shooters-effective against individuals but ineffective as a means of achieving political change" (Davies 2001: 399). Giselinde Kuipers maintains almost the same attitude but from a Bourdieusian perspective as she views humour as a marker of social boundaries and is related to taste, habitus and existing power relations, arguing that "humor tends to follow social hierarchies: people generally joke 'downward' rather than "upward"" (2011: 71). She argues that in repressive societies humour has no real political effect and that in open societies "joking is more likely to transcend boundaries and mobilize people" (2008: 374). Drawing on Sigmund Freud's seminal work on jokes, Samer Shehata concludes that "[p]olitical jokes might not be able to topple dictatorial regimes, but they do provide solace from their oppression" (1992: 76).

As such, humour has no political effect but highlights how society views and organizes itself. Humour is thus a social fact, a marker of boundaries or an indicator of where social tensions in a society lie, and needs not be a mechanism of resistance. It can, at best, function, from a Bergsonian or Freudian perspective, as a social corrective, a relief from tension or a safety valve, whereby the existing social order can survive and persist. While this can be, to some extent, true in times of political stability, it does not account for the role of humour in bringing about political change in light of its long-term cumulative effects. Davies persists in maintaining that "jokes are thermometers, not thermostats" (2010: 10). Though, talking about the fall of the Soviet Union, he might well acknowledge that jokes are "a harbinger of collapse" 
(2010: 13), he still considers them as "a very weak force in a world of much stronger forces" (2010: 15) and explains the fall in terms of a combination of other factors.

Other approaches view humour as a space of freedom and resistance. Though Dustin Griffin denies any immediate effect of satire, he argues that: "perhaps we need to distinguish between an intellectual and a practical subversion. There is reason to believe that ideas have power, and that in the long run they can move mountains and topple tyrannies" (1994: 158). James Scott maintains that, among other practices, everyday humour is a form of cultural resistance and constitutes what he calls "the hidden transcript" (Scott 1990: 4), which is the apocalyptic discourse of doom for the oppressor internalized by the subordinated. He admits that the effect of such everyday practices is silent and slow but capable of wearing down the power of the powerful and compelling them to give a few concessions. This hidden discourse may break out from secrecy into public defiance when power becomes vulnerable during a troubled period of political unrest (the Arab spring is a case in point).

This hidden unofficial worldview was highlighted by Mikhail Bakhtin in his book, Rabelais and His World, where he describes the border clash between two hostile forces: official and unofficial. He opposed the official feast that "asserted all that was stable, unchanging, perennial: the existing hierarchy, the existing religious, political and moral values, norms and prohibitions" (1984: 9) to the true festive character of the carnival where "the entire world is seen in its droll aspect and its gay relativity" (1984: 11). Bakhtin insists on the relation of the carnivalesque laughter to freedom, renewal, the suspension of hierarchies and the gay relativity of norms and values. As such, the carnivalesque, with its logic of "inside out" (1984: 11), breaks up, to cite Michael Holquist, "official lies and the narrow seriousness dictated by the ruling classes" (1984: XXII).

Satire can be best apprehended as a discourse in the larger framework of power and subversion whether it highlights a social structure or represents a counter-hegemonic practice. If power, in the Foucauldian sense, is not only the power of vested authorities, violence and tyranny from above but also, and specifically, the distribution of certain forms of knowledge by means of discourse by largely unseen forces in a social system, satire as a form of resistance is then part of a dynamic interplay of power and subversion. To put it differently, satire can thus affect the workings of power in a long-term process. It is a field whereby forces interact in a continuous dialectic over time replacing existing contradictions with new ones.

The analysis of the modes of satire in this paper is based on the notion of satire as pregeneric and modal, and as "mental position that needs to adopt a genre in order to express its ideas as representations" (Knight 2004: 4). It follows that satire is basically a "frame of mind" (Knight 2004: 1) or "an attitude" (Frye 2000: 310) and thus "an exploiter of other genres" (Knight 2004: 4). The analysis of modes was conducted, accordingly, on 432 posts published in the two community pages mentioned earlier, as this can give more insight into the use of satire as a collective practice in a sustained context (see Appendix).

In fact, satire changes its strategies and attitude in terms of the political context. To apprehend the changes that take place in the workings of satire, Northrop Frye's typology will be used as a theoretical framework for the analysis of the different types of satire used by Facebookers during settled and unsettled periods. The first type of satire is the satire of the low norm which corresponds, according to Frye, to "ironic comedy" and which "takes for granted a world which is full of anomalies, injustices, follies, and crimes, and yet is permanent and undisplaceable" (Frye 2000: 226). If this type of satire accepts conventional norms and attacks anomalies, the second type, which Frye calls "the second or quixotic phase of satire" (Frye 2000: 230), challenges social conventions directly and discredits their sources. Ideologies are juxtaposed with the practicalities of experience and their claims to truth are undermined. The third type of satire is "the satire of the high norm" (Frye 2000: 234); it turns the world upside down and undermines what we think is common sense. It involves obscenity, scatology and 
disease bringing us down to a "bodily democracy paralleling the democracy of death in the danse macabre" (Frye 2000: 235). The use of these three types of satire to analyse and classify the different satirical practices on Facebook will bring to light the strategies used and the political attitude of the satirist toward the changing power relations in Morocco during the fouryear period.

To apply these theoretical premises to the Moroccan context, it is necessary to check them in terms of three main variables: a) Moroccan authoritarianism (political context), b) the use of social media by Moroccans (patterns of access), and c) the outbreak of the Arab Spring (historical process). The study of these variables will show how the workings of satire have changed in response to its changing conditions of production and reception. Besides, it will not only register the existing differences between the satirist and the object of satire, but also the difference satire makes (Bogel 2001) as a subversive critical discourse in the cultural schemata that govern both of them.

The Moroccan political regime is a monarchy that is ideologically based on "the existence of a direct relationship, sanctioned by divine decree, between the sovereign and his subjects" (Hammoudi 1997: 12). This relationship is established by the solemn oath of allegiance (bay'a) which establishes the monarch as the "commander of the faithful" (Waterbury 1970). However, this allegiance is based on a consensus whereby "the community transcends its divisions through obedience to this sacralized authority" (Hammoudi 1997: 13). The monarchy, called the Royal House (Makhzen), has to stay above civil society, political parties and its power struggles, which can be seen as a political exercise of power that maintains balance. However, it maintains the rivalry between the civil and political networks and assumes the role of arbiter between them. Besides, even if "ministers have increasing responsibility for daily affairs, major decisions and fundamental choices are in the hands of the sovereign assisted by his advisors" (Hammoudi 1997: 21). James N. Sater argues that "competing political parties apparently justify and reinforce the king's role as an arbiter" (2010:2).

In addition to its role of arbitration, the monarchy is the "central character in a patronage system, capable of restraining or putting at a disadvantage any political parties or unions that might challenge its power" (Hammoudi 1997: 33). Nonetheless, the relationship of the monarchy to other networks is pragmatic rather than ideological in that it distributes resources and power in terms of the loyalty of these networks. This relationship is based on three principles: closeness, service and gift. The notables, with whom the monarchy is allied, must build "closeness through gift exchange", give "evidence of good and loyal services" and "go through a display of ritualized submission" (Hammoudi 1997: 134).

Accounting for the prevalence of this authoritarian system in Morocco, Abdellah Hammoudi argues that the dominance and submission relationship can be best explained by a set of cultural schemata, among which the master-disciple schema is the most salient (which is akin to what Foucault calls a "diagram'). Excluding the economic factor (as the underprivileged are patient, despite inequalities, and hope for the best), Hammoudi maintains that the relationship of master and disciple that prevails in mystical practices and its values of submission, closeness, service and gift exchange, articulates all power relations and tactics in Morocco. However, he highlights its ambivalence (the disciple might plan to replace the master) as it wavers between submission and rebellion (military coups, riots and the Arab Spring). Conversely, Sater argues that this relation is based more on performance than exclusively on religion and history, stating that it is rather a "patron-client relationship" (Sater 2010:2).

Reversing Hammoudi's argument (master-disciple schema), Malika Zeghal asks the following question: "What happens... when spheres of political competition are opened up and political mediation is institutionalized through a more free press, partisan pluralism, and elections?" (Zeghal 2009: 597). She contends that "under these new conditions these spheres 
are exactly what allow authoritarianism to continue to function. Authoritarianism reproduces itself in new forms" (Zeghal 2009: 597). However, reacting to the challenges to its hegemony, the state "uses a variety of strategies: accommodation, appropriation and the definition of boundaries beyond which a public discourse and a public challenge to the state's hegemony are prohibited" (Sater 2007: 1). These strategies require, according to Sater, the state's engagement in these discourses that challenge its hegemony. As a catalyst for political change, this participation changes the state's hegemony and "the relationship between the state and the society, as well" (Sater 2007: 2). Traditionally the political scene was divided between two main forces: the Makhzen (the state power) and Siba (dissent; literally meaning "disorder"), and the latter was always cracked down severely. In modern Morocco, the dissent has been mediated by partisan politics and a rather "muzzled" civil society.

The relatively open political scene that Morocco has witnessed since the ascent to throne of the young king in 1999 has not resulted in more freedom for satire, and yet the boundaries have been pushed by some scattered instances of attack against the monarchy. For example, the satirical newspaper, Demain, and its Arabic version, Dumane, launched by Ali Lamrabat respectively in 2000 and 2003, challenged power-holders openly. On publishing a cartoon deriding the monarchical institution, Lamrabat was sentenced to three years' imprisonment and a fine, but was released by a royal pardon in 2004. Other examples include Tel Quel, a magazine run by Ahmed Benchemsi that is relatively audacious; Le journal hebdomadaire, edited by Aboubakr Jamai, against whom many lawsuits were filed and whose newspaper, banned many times, went bankrupt and out of business in 2010; and the stand-up satirist Ahmed Snoussi (nicknamed Bziz), who has been banned from television because of his direct challenge to power.

The policing of satire has been done in terms of legal (e.g., affront to public decency), religious (sacrilege) and political norms (instilling cynicism in the public). This repressive context, where access to discourse in the public sphere is controlled, has led satirists to practice self-censorship and play with the boundaries by shifting their attacks to soft targets, such as state officials and ministers. Because the expectations were very high in the beginning of the new era and the subsequent changes were deemed insufficient, a large number of the population, especially the young, lost interest in politics and resorted to alternative media, especially enabling ones like the social networking sites.

Generally speaking, social media have opened up a new "platform for public self expression" (Shifman 2012: 189) and have increasingly become a symbol for participatory culture. Henry Jenkins argues that participatory culture, which contrasts with older notions of passive media spectatorship, is based on media convergence, that is "the flow of content across multiple media platforms" (2006: 2), including social media, where citizen satirists publish appropriate media content and make it serve their critical ends. This active participation of social media users in creating and circulating content can culminate in what Ryan Milner refers to as "a counterpublic model of mediated public discourse" (2013: 67). This user-generated bottom-up content can be used, according to what Milner calls "the logic of Lulz" (2013: 62), for antagonistic ends, repressing minority values and discourse, or, alternatively as agonistic engagement promoting adversarial pluralism.

However, in the Moroccan context where such space for public self-expression was desperately needed, the use of social media was very limited before the Arab Spring. People attributed the use of these media to young people and were thus suspicious about their relevance as a space for counterpublics. Open dissent was exclusively performed by what Elisabeth Noelle-Neuman calls "the hard core" (1991: 271) and the majority was reduced to silence. According to her theory of "the spiral of silence", people are unwilling to express their opinion if they view that their opinions are losing ground. They keep silent because they fear isolation. Public opinion as the dominating opinion has become an invisible law in Morocco that, 
according to Noelle-Neuman, "threatens the dissenting individual with isolation, the politician with loss of popular support." (1974: 44)

In Morocco, the silent majority fears not only isolation but also reprisal, and a large population segment keeps silent out of a desire to identify with the powerful. Others have migrated to the virtual world, specifically Facebook, where they promote social relations with a relative disregard for politics. Their everyday resistance has taken advantage of digital technology to create new satiric forms. The satiric posts that Facebookers publish as status updates "re-mediate" everyday resistance practiced in the real world by giving it a digital form and a virtual context. The posts are generally composite, multimodal, at times intermedial using the techniques of other media, but create original satiric forms where graphics editing programs like Photoshop are used to manipulate pictures and create new virtual satiric realities. Besides, the posts (akin in structure to "memes" studied by Milner (2013) and Shifman (2012)) may combine text, pictures or drawings from different sources in an original comic assemblage. Far from being either poets or engineers, Facebookers use their creative imagination and tinker with whatever tools available to resist domination and criticize social ills. Satire is no longer the preserve of the artist; rather it has become the work of ordinary citizens which combines individual creativity and collective imagination and intelligence. Facebookers are, to use Michel de Certeau's words, "always on the watch for opportunities that must be seized" or they "manipulate events in order to turn them into opportunities" (de Certeau 1984: xix). They actually turn the "actual order of things" to "their own ends" (de Certeau 1984: 26). The discourse of the dominant elite, their practices, and policies are tracked, accommodated and transformed into satiric content.

As Facebook was heralded as a zone for free expression, more people joined it in Morocco and their number rose from 2,283,780 in 2010 to 5,250,340 users in 2013 (see Figure 1; Mansouri 2013: 65).

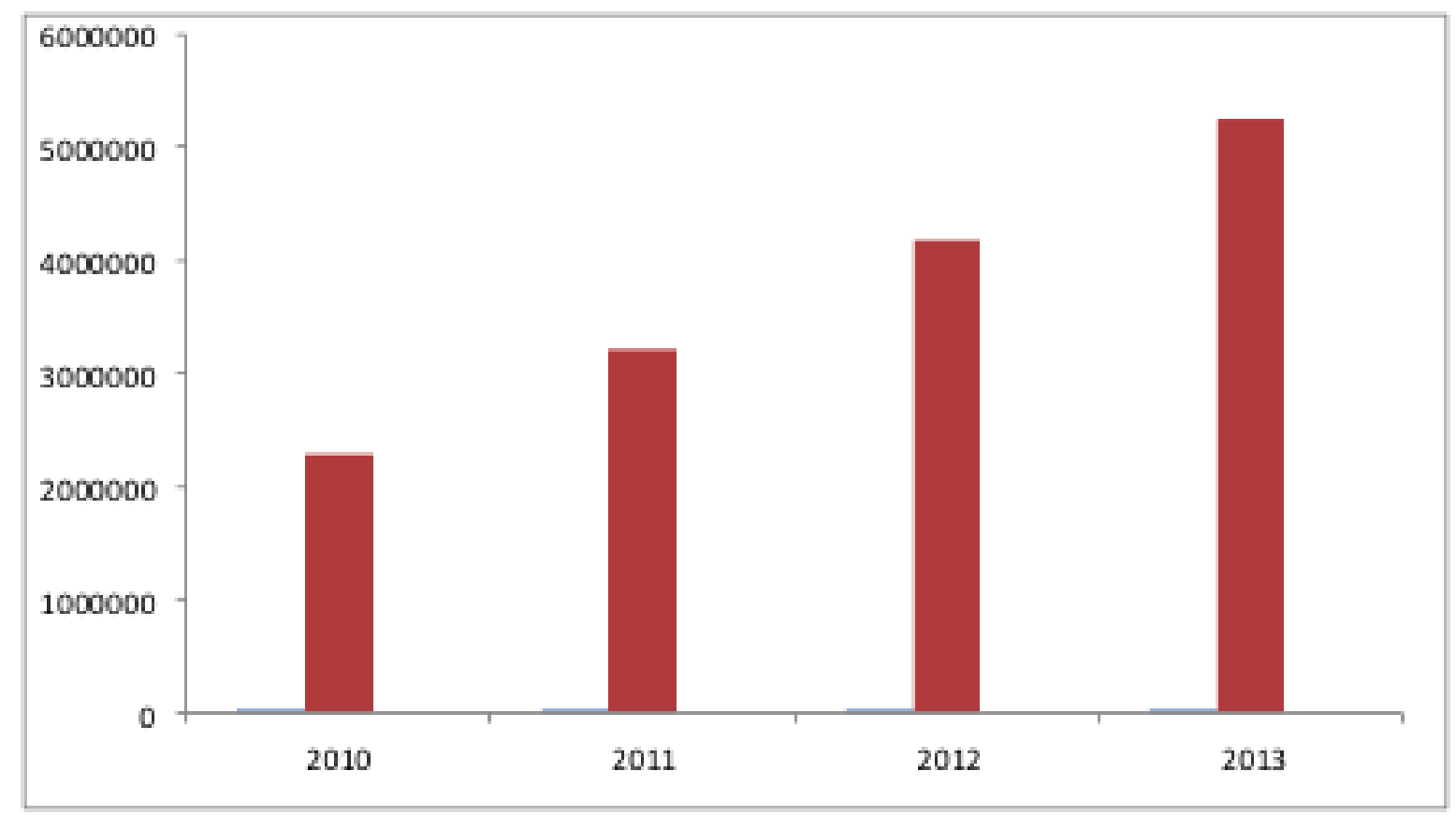

Figure 1. The gradual rise in the number of Facebookers in Morocco

This dramatic rise was due partly to a real change in the approach of the people to politics. Before the Arab Spring, most people were indifferent to politics because they believed that political change would never happen as politicians were deemed corrupt and self-serving. The 
Arab Spring restored the lost faith in political change and Facebook enhanced this change in people's attitude by allowing them to laugh overtly at those who dominated them for ages and were beyond rebuke.

\section{Political changes and adaptive strategies of satire}

As the main focus of this research is to know how the ratio between conformist and subversive satire changed over time and how the target and tone of satire have changed throughout the Arab Spring, the analysis was based on a clear time line divided into three distinct periods.

\section{Before the Arab Spring: light-hearted low-norm satire}

Before the Arab Spring (2010 to February 2011), resistance to domination was mostly disguised and displaced on Facebook. In a study conducted by Arab Thought Foundation in 2010 (Mansouri 2013: 41-42), the "expression of feelings" ranked first among 35 topics that caught the interest of Arab Facebookers while the category of "political issues" ranked 18. The study shows that the Arab young people were more interested in the fulfilment of their personal needs than in political engagement. They sought entertainment and better ways to manage their personal life (advice on health, food, religion and internet) (Mansouri 2013: 44).

The study of collected data (2010) shows that while the young were interested in promoting their personal life, they were also engaged in socio-political life, focusing particularly on issues like corruption and unemployment. The use of satire was limited in terms of tone, issues and targets as Facebookers tended to frame their satire in terms of the then prevailing conventions that confined humour to light-hearted tone, decent language and typical targets. Most satirical posts avoided attacking historical particulars or using obscene language as the aim was generally a combination of critique and entertainment. ${ }^{1}$

The first example of this type of satire (Figure 2) shows a road sign indicating the name of the next village which reads: shafarni in Arabic, meaning "he robbed me".

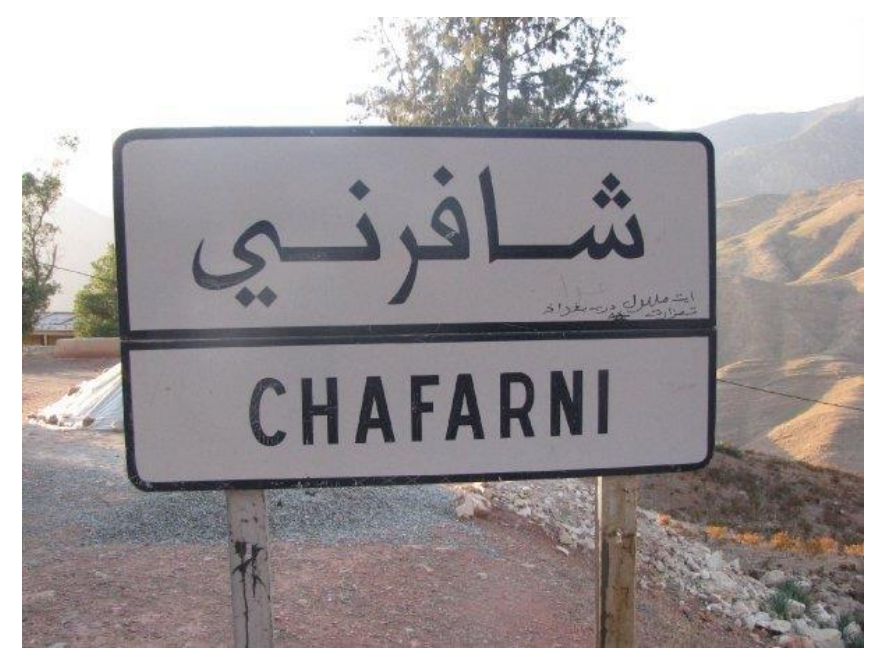

Figure 2. A road sign of the next village changed into a protest sign

The text in the road sign is framed as humorous and depends for its effect on the perception of what Elliott Oring calls "appropriate incongruity" and defines as "the perception of an appropriate relationship between categories that would ordinarily be regarded as incongruous" (2011: 1). The name of this village might have been photo-shopped on the sign (as its existence 
could not be verified); however, the name might be real as a lot of villages in the mountains have Berber names and mean differently to the local Berber inhabitants. As a name, it is both appropriate (in Berber) and incongruous (in Arabic); the foregrounding of the name and the omission of any information about the village reveals the humorous intent of the user. The post insinuates that the inhabitants have chosen a name to their village that changes the road sign into a protest sign, denouncing the prevailing corruption.

By and large, this type of satire remains within the range of the first type of satire in Northrop Frye's typology, that he labels "the satire of low norm" (Frye 2000: 226), whereby the satirist's attitude "fundamentally accepts social conventions but stresses tolerance and flexibility within their limits." (Frye 2000: 227). Other posts exposed, with a satire prevailingly light in tone, social ills like corruption, bribery and favouritism. One reason for the lack of subversive satirical practices is the indifference of the young to the global political issues and their interest only in partial and local aspect of corruption. Their disengagement from (bad) politics derives from their incredulity toward politicians and their disgust at their doubledealing and corruption. This cynical attitude, which the state fears so much as it may damage 'democracy', is itself a form of resistance. The cynical is paradoxically manifest in an engagement to an infrapolitics of light-hearted form of satire which exposes the abuses of (bad politics) and laughs at them.

\section{During the Arab Spring: public high-norm satire}

When the Arab Spring broke out, Moroccan Facebookers were perplexed by the rapidly changing situation. However, two main categories emerged. The first category includes Facebookers who were reluctant to challenge the system as a whole because they were partly crippled by uncertainty, and were thus tentative in their claims of political change. The second category, including already hard-core non-conformists from radical Islamist and leftist movements, practiced subversive, carnivalesque satire to give voice to some radical claims, ranging from deriding constitutional monarchy to radical change.

Guided by a burgeoning hope in (good) politics, the first category pushed the limits of their satire as to attack practices that were responsible, in their eyes, for the deterioration of the situation. Satire became more topical and targeted real politicians, rarely daring to overstep the red lines as to attack the monarchy. This type of satire is akin partly to what Frye calls "the second or quixotic phase of satire" (Frye 2000: 230) as they both challenge the social conventions and dogmas, set "against the life they are supposed to explain" (Frye 2000: 230). The democratic process, declared to be underway, is questioned by Facebookers in terms of the actual practices of politicians themselves. Parliamentary members are depicted in many posts as having naps in Parliament. 


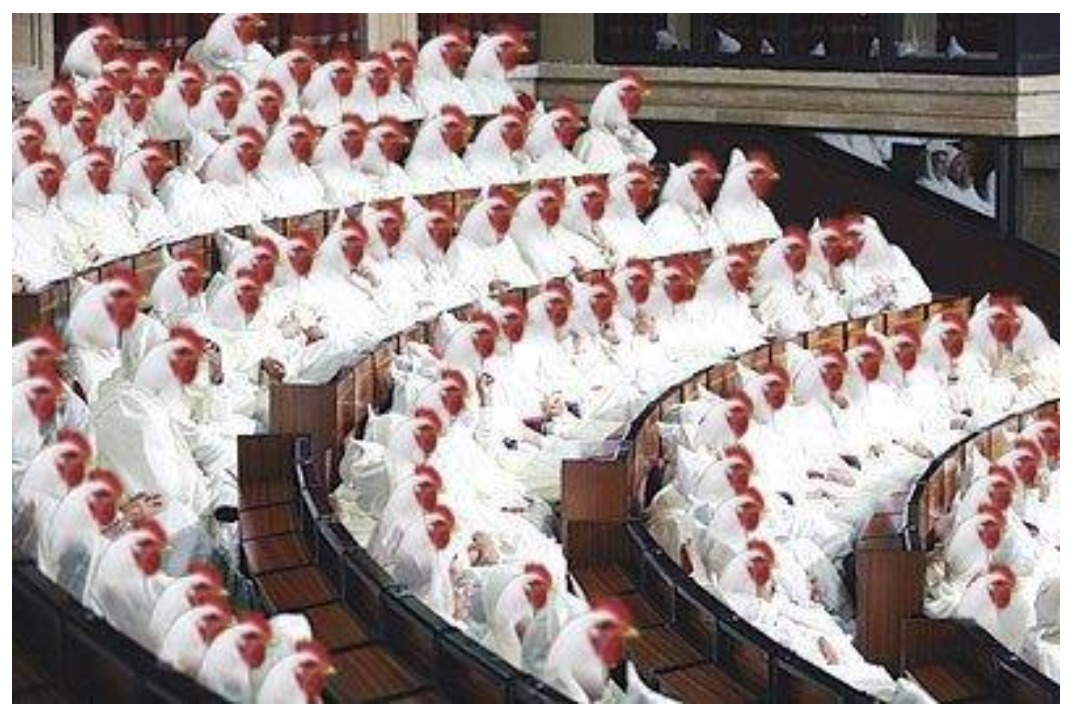

Figure 3. Photo-shopped photo of parliament members depicted as chickens

One post compares them to helpless chickens (Figure 3), generalizing the blame to all of them. Photo-shopped as it is, the post reveals a prevailing attitude that politicians are submissive and inefficient. The animalization of these politicians as white chickens serves to stress their subordination to the Makhzen.

It should be noted at this stage that the system of power in Morocco has a double layer structure, with a deep stable powerful component (the Makhzen institution) and a surface changing configuration (political parties and representative institutions). The first category of Facebookers hold partisan politicians accountable for the mismanagement of the situation. Even if their satire can verge on the carnivalesque, it is contained within the limits of the permissible, with some freedom of opinion that "do not challenge the powers of the royal family" (Hammoudi 1997: 21). Facebookers have apparently internalized the fact that the monarchy is beyond rebuke and should stay above political parties to maintain balance and provide arbitration. Yet some of them have pushed the boundaries a little further and resorted, taking advantage of the freedom enabled by Facebook and the Arab Spring, to grotesque exaggeration.

In effect, the second category gave vent to their feelings of anger and frustration. The elements of aggression, play, laughter and judgment (Test 1991: 31) characterize their direct satire of the political system as a whole. 


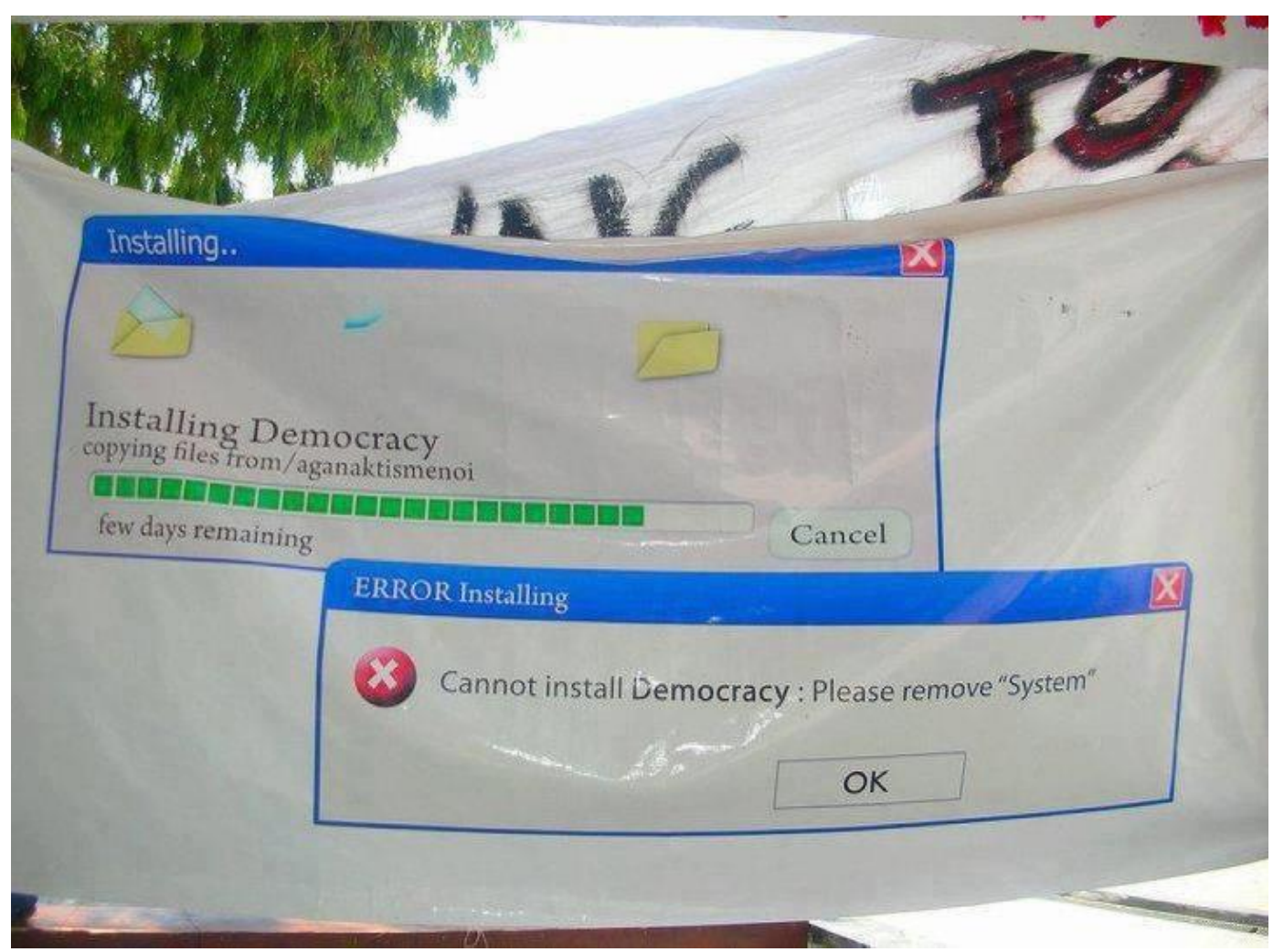

Figure 4. A parodic post attacking the regime and questioning its legitimacy

Figure 4 exemplifies this unprecedented satirical impulse to articulate radical claims, attacking the system in a new digital mode that evinces a change in the nature of satire. The intermedial character is attention-grabbing; the post uses an electronic dialogue format to attack the regime. The computer announces that the installation of the program "Democracy" has failed and demands that the "system" should be removed. The parody, defined as "the imitation of form with a change to content" (Rose 1993:43), makes use of an electronic language and format to question and subvert the system. While this post is serious in its political implications, it does not use explicit grotesque imagery. Other posts, though, are more aggressive using animalization and physical photo-shopped distortions. This savage satire, called "the satire of the high norm" by Frye (2000: 234), was exclusively used by few hardcore activists who joined the February 20th Movement, and contested the regime by attacking, in a carnivalesque mode, some practices and rituals of the monarchy they deemed archaic and undemocratic. The February 20th Movement is the Moroccan incarnation of the Arab Spring. It was comprised of small political parties from the radical left and the Islamist movement of Justice and Spirituality. The latter withdrew from the Movement after the elections of 2011. The Movement organized protests from 20 February 2011 to the spring of 2012.

During this unsettled period, Facebookers' comments on satirical posts reveal the great divide that characterized the political scene. The close study of these comments shows, via the coded categories, the ideological mechanisms used by the supporters of monarchy and its opponents. Facebookers who defended the King strongly argued that he was not sacred but should be respected. They also asked the opponents to compare Morocco to other unstable countries where the Arab Spring upheavals toppled the rulers. The comparison serves to highlight the political stability that prevails in Morocco.

Conversely, the opponents focused on the moral denigration of the supporters, depicting them as slaves worshipping the monarchy. Their resistance was mostly open but based on eschatological morality, claiming an inevitable fall of injustice. While the supporters were 
more historicist, the opponents tended to be essentialist, cherishing values that pertained more to religion and morality. The attitudes of Facebookers toward humour are telling as the defenders of monarchy viewed humour as a negative practice and even an expression of "virtual courage". This should be understood as a mechanism of intimidation practiced by the supporters. They argued that because humour is used to make fun of a respected figure, it is illegitimate and labelled it "Hlaki humour" (meaning "very bad, low-brow humour").

This controversy shows how humour is entangled with power relations and struggles and that satire is perceived as a real threat to the stability of the regime. The subversive satirical resistance to power can be felt in the strong reactions of the supporters of the monarchy, which shows that satire is a real challenge, and that the power holders perceive it as such.

\section{Blame-shifting, scapegoating and resistance to subversive satire}

The elections held on 25 November 2011 were a turning point in the Arab Spring in Morocco, when an Islamist party won the elections and formed a coalition government. Satire changed targets gradually, as most satirical posts were directed at the Islamist Prime Minister. Thus, the satire of the monarchy started to lose effect, especially after the withdrawal of the Islamist movement Justice and Spirituality from the February 20th Movement. Subsequently, many hardcore activists were arrested and sent to prison, the rapper Mouad Belghouat (nicknamed El haked) being a case in point.

The workings of satire were then conditioned by the political attitude of the satirist toward the new reality. Those who were content with the constitutional reforms criticized the Prime Minister for his blunders and miscalculations. The few hardcore activists, mostly from the radical left, persisted in their savage satire of the regime, claiming that the reforms and the elections were just a political "hoax" or manipulation. Other disappointed Facebookers resorted to black humour and bitter irony and sarcasm.

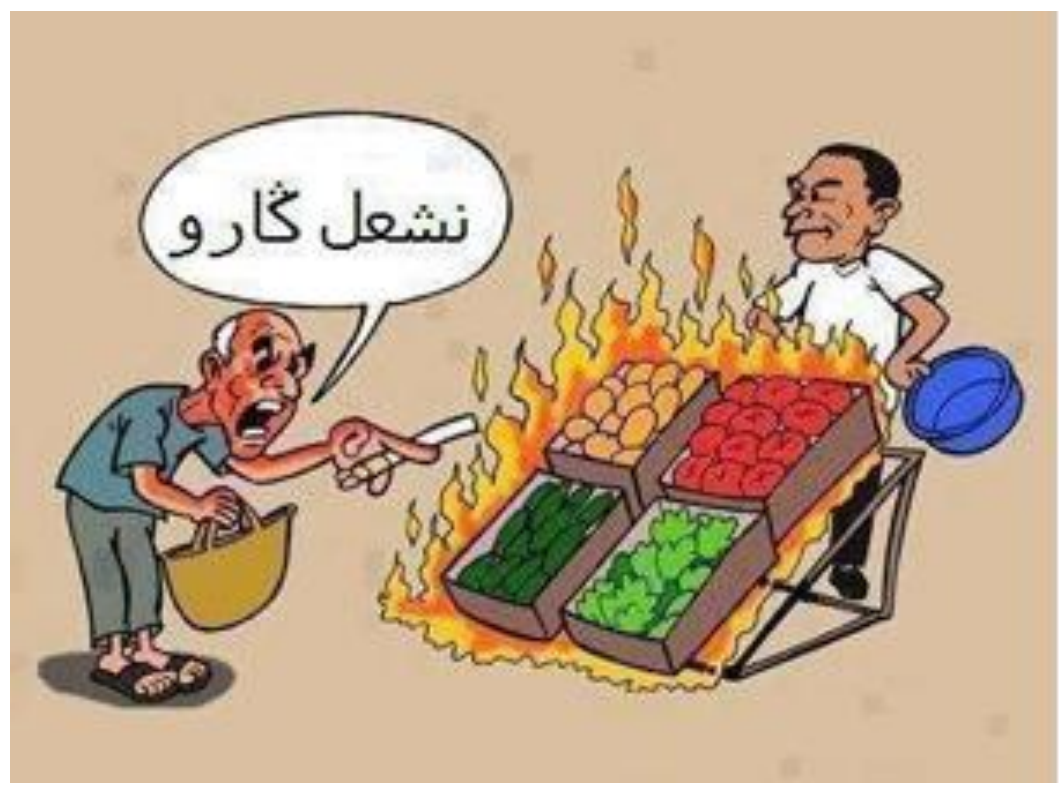

Figure 5. A comedic critique of the government decision to raise prices

Most satirical posts pertaining to the former category do not seek to question the burgeoning consensus but only denounce the misuse of power. In Figure 5, Facebookers denounce the rise in prices by transposing a verbal metaphor into a visual form. As vegetables, a staple food for 
Moroccans, are sold at "burning prices", the price-conscious shopper takes the metaphor, often used by Moroccans, at face value and responds by asking the permission from the greengrocer to light his cigarette from the burning fire (prices). The comic effect is obtained by taking "literally an expression which was used figuratively" (Bergson 2014: 36b). The cartoon draws, with considerable effect, on the collective imagination of Moroccans where high prices and the metaphor of 'fire', connoting punishment and suffering, are related.

The latter category of hardcore Facebookers continued to instil scepticism in the public by mocking the political reforms. Figure 6, for example, is a photo of a woman having her shoes polished by a shoe polisher, with the following caption placed below: "Hajja ('respected woman') is implementing the principle of gender equality guaranteed by the new (given) constitution at the shoe polisher's". The commentary makes the photo ironic. As a matter of fact, the post is an "echoic mention" (Sperber \& Wilson 2012: 5) of the promises of the new constitution adopted by a referendum in Morocco in 2011 and the expectations for freedom and social equality it created. It is satirical in that it expresses a mocking toward the object being mentioned.

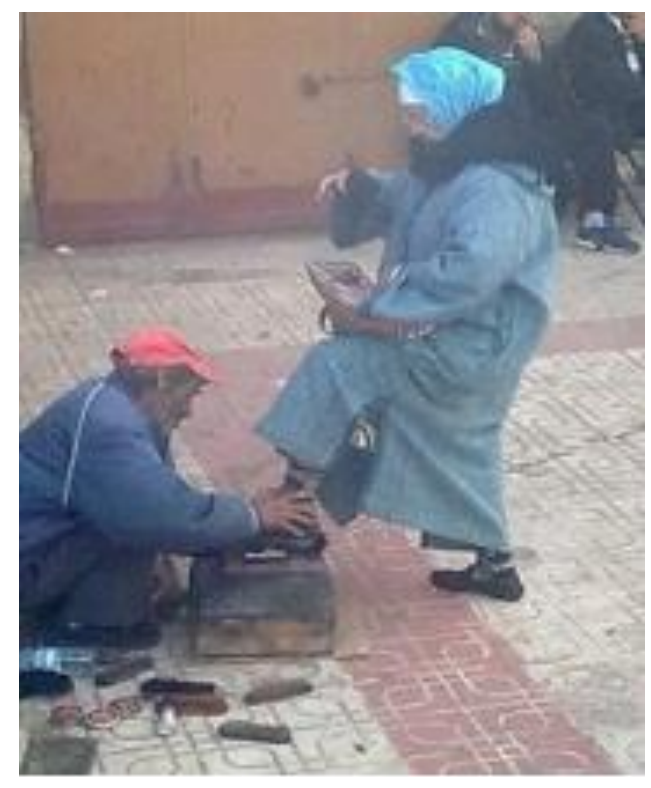

Figure 6. Ironic commentary on the implementation of the new constitution

Adding captions to photos is a common practice on Facebook; the comic effect often stems from the combination of a photo and a text which are ordinarily regarded as incongruous. Facebookers keep changing captions for comic effect, as is the case with the photo of this woman which was shared and slightly modified, but not all the variants have had the same rate of circulation. Demonstrators' banners or protest signs were also used by Facebookers; for example, a picture of a man holding a protest sign made of a slice of thick cardboard, asking "to topple the people", a claim that ironically echoes the famous Arab Spring slogan "The people wants to topple the regime". Different commentaries were added to the picture and were posted highlighting its political implications. This link between the online satire and the street demonstrations endows satire with a pragmatic and discursive agency, as it inspires, and is inspired by, claims articulated in street protests.

Feeling defeated by the hostile reality, other Facebookers used black humour to denounce its cruel meaninglessness. They pretend to believe, with a humorous detachment, that this absurd reality is the ideal. In Figure 7, the fishing boat teeming with illegal immigrants to Europe brings to light the tragic fate of a hopeless generation who prefer to risk their life in a 
dangerous sea crossing than endure poverty. The post is a montage of a diverted photo from the media and a humorous comment ("Unable to provide fish for the citizens, the government has managed to provide citizens for the fish"). The incongruity between the jokey tone and the serious subject matter betrays the cold, self-deprecating mood of a segment of Facebookers who sympathize and identify with the victims, mostly young people, of the policies of the government. By describing the tragic fate of these illegal immigrants in a Swiftian, shocking style, the post is but a damning indictment of these policies.

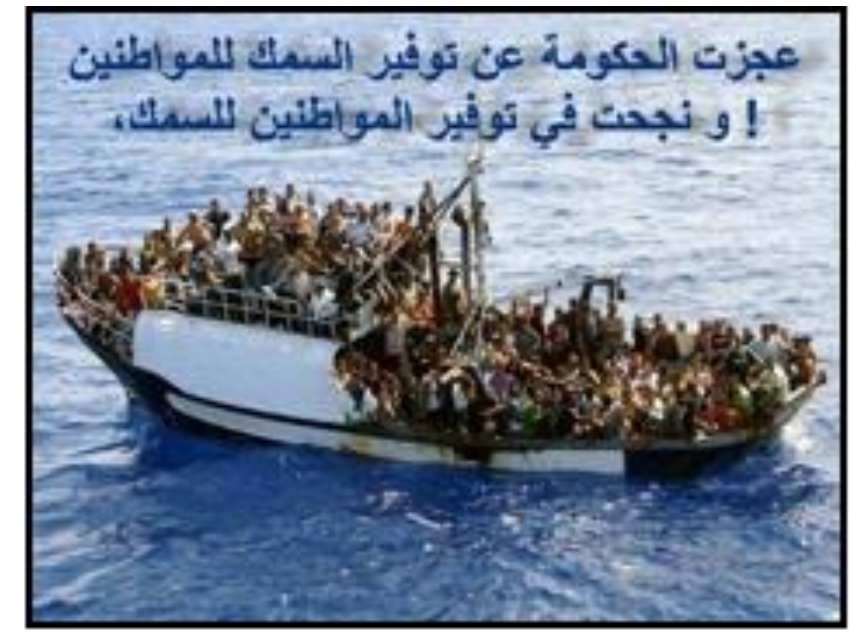

Figure 7. The use of black humour to denounce the government policies

The study of the comments posted in response to the satirical posts in this period shows that Facebookers have shifted their critique to the Prime Minister. This blame-shifting is significant in the Moroccan context as the ministers are considered to be servants of the monarchy. Facebookers blamed the Prime Minister because they felt that he was not serving the people that elected him but solely serving the Makhzen (hence expressions like: puppet, dog, servant of Makhzen...). The blame-shifting has altered the workings of satire; the monarchy is gradually spared and the attack is directed at its subordinates and servants. Facebookers attack the most accessible political figure, offered by the regime as a scapegoat.

The feeling of disappointment has generated a self-deprecating attitude of self-blame and collective guilt. Some Facebookers view the Moroccan people from that angle describing them as docile, short-sighted, and even cursed. Because satire is deeply rooted "within a context of expectation, convention and local understanding" (Quintero 2007: 10) shared by the intended audience, it can become totally undesirable if it is based on ideological hatred, propaganda and uncertainty. The bloody struggles in other Arab countries have undermined hardcore satire, for people have been led to prefer stability, even with limited freedoms, to total anarchy. The analysis of hardcore subversive satirical posts shows that this type of satire has become occasional, popping up once an event involving the monarchy is hyped by the media or goes viral in social sites, like the annual celebration of allegiance or the pardon accorded by the monarch to an imprisoned Spanish pedophile (in 2013). ${ }^{2}$

\section{A persisting cultural model}

A comparative study of the different trends of satire in terms of targets was conducted on the collected data. Figure 8 shows how satire changed targets from 2011 through 2014, highlighting a significant decrease in targeting the monarchy after the elections and the steady targeting of the Prime Minister. Other targets were also satirized but do not form distinct 
categories, as they are typical butts related to issues like corruption, radical Islamism, gender inequalities, for which the government is also held responsible. Hammoudi's model of the power relations in Morocco may account for these political behaviours where the monarchy, especially in settled period, remains, in the eyes of the majority of Moroccans, above the political struggles while politicians are seen as corrupt and opportunistic trying to get closer to the monarchy to serve their own interests. The blame-shifting observed in the practice of satire after the elections is in line with the cultural schemata that govern power relations in Morocco. The monarch/master should be respected and the blame for any mismanagement should be directed at his servants.

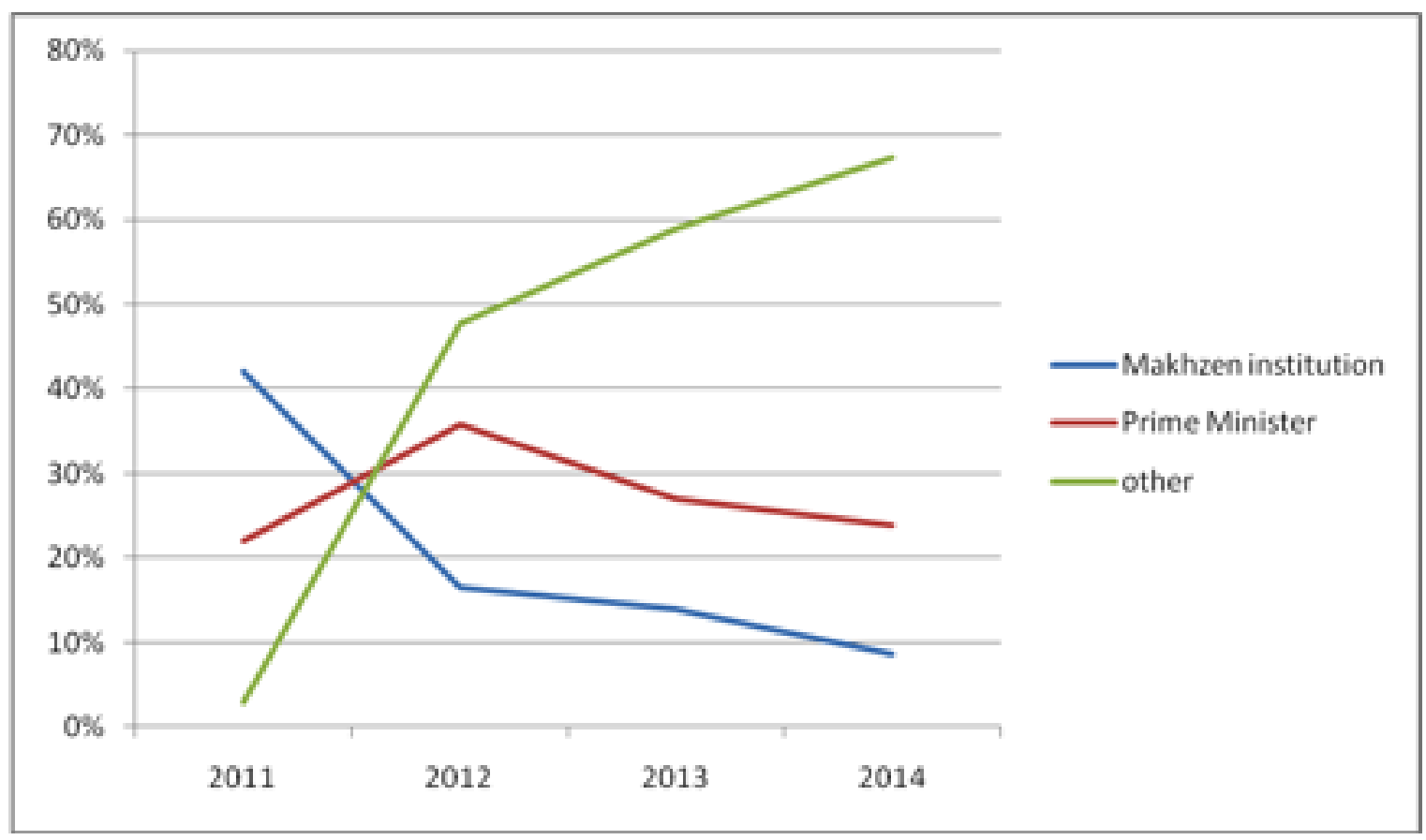

Figure 8 . The change in satirical targets over four years

\section{Conclusion}

Satire is subject to many constraints that shape its workings. Political satire may thrive "under limited repression or censorship" (Griffin 1994: 140) and in response to the "forbidden fruit" principle (Draitser 1998: 5-6); yet the boundaries are not only political but also cultural, sociopragmatic, psychological and historical. The freedom that Facebook provided for Moroccans satirists allowed them to overstep some policed boundaries and ruffle powerful feathers; however, the dissemination of the news of civil wars instilled fear and uncertainty in most Facebookers, who, because their mindset is shaped by the prevailing cultural schemata, shifted the blame to soft targets, and practiced satire in its different modes, including grotesque degradation. Yet their satire was perceived as subversive only when it challenged the real power holders (called "the deep state" in Morocco). Partisan politicians are the scapegoats who accept to carry the blame for any crisis as this is how they maintain closeness, according to Hammoudi's schema, to the monarchy. Some "folk devils", as Stanley Cohen would name them (2002: 2), persisted in overstepping the red lines, but had to face an unresponsive audience, which set a new boundary for their satire. This indicates that if digital satire is to be viewed as resistance to domination in the arena of ideological struggle, it should accept its status as an ideological discourse and face the consequences. Satire may not be effective if it 
supposes that its views are shared by all the public. The Facebook audience, as has been shown earlier, eschewed expressing "likes" for subversive satire because they felt that the ideology underpinning it was not in line with their desire for stability.

\section{Notes}

${ }^{1}$ Figures 3,4,6,7 were downloaded from https://www.facebook.com/sarkha20 (Accessed on 23 October 2011, 23 June 2012, 6 April 2012 and 8 June 2013, respectively). Figure 5 was downloaded from https://www.facebook.com/pages/Lapresspro, in December 2012. Figure 1 was shared and downloaded on 23 October 2010. 432 out of 578 posts were downloaded from these two Facebook community pages: https://www.facebook.com/Humour.Politique and https://www.facebook.com/sarkha20.

${ }^{2}$ Daniel Galvan, a retired Spanish professor, was convicted for raping 11 Moroccan children and sentenced to 30 years in prison in September 2011. He was released in August 2013 by a royal pardon. Hundreds of angry demonstrators protested outside the parliament and the King revoked the pardon for the Spanish pedophile.

\section{Appendix}

Rates of the use of satirical modes by Facebookers throughout the four year period

\begin{tabular}{|c|c|c|c|c|c|}
\hline Modes & 2011 & 2012 & 2013 & 2014 & Total \\
\hline The comic & $\begin{array}{l}24 \\
72.72 \%\end{array}$ & $\begin{array}{l}67 \\
56.77 \%\end{array}$ & $\begin{array}{c}114 \\
50.89 \%\end{array}$ & $\begin{array}{l}30 \\
52.63 \%\end{array}$ & $\begin{array}{l}235 \\
54.39 \%\end{array}$ \\
\hline $\begin{array}{l}\text { The } \\
\text { carnivalesque }\end{array}$ & $\begin{array}{l}3 \\
9.09 \% \\
\end{array}$ & $\begin{array}{l}17 \\
14.40 \%\end{array}$ & $\begin{array}{l}40 \\
17.85 \%\end{array}$ & $\begin{array}{l}12 \\
21.05 \%\end{array}$ & $\begin{array}{l}72 \\
16.66 \%\end{array}$ \\
\hline $\begin{array}{l}\text { Irony, wit, } \\
\text { sarcasm, } \\
\text { black humour }\end{array}$ & $\begin{array}{l}4 \\
12.12 \%\end{array}$ & $\begin{array}{l}12 \\
10.16 \%\end{array}$ & $\begin{array}{l}36 \\
13.07 \%\end{array}$ & $\begin{array}{l}3 \\
5.26 \%\end{array}$ & $\begin{array}{l}55 \\
12.73 \%\end{array}$ \\
\hline Contrast & $\begin{array}{l}2 \\
6.06 \%\end{array}$ & $\begin{array}{l}6 \\
5.08\end{array}$ & $\begin{array}{l}15 \\
6.69 \%\end{array}$ & $\begin{array}{l}8 \\
14.04 \%\end{array}$ & $\begin{array}{l}31 \\
7.17 \%\end{array}$ \\
\hline Parody & 0 & $\begin{array}{l}10 \\
8.47 \%\end{array}$ & $\begin{array}{l}8 \\
3.57 \% \\
\end{array}$ & $\begin{array}{l}3 \\
5.26 \%\end{array}$ & $\begin{array}{l}21 \\
4.86 \%\end{array}$ \\
\hline Word play & 0 & $\begin{array}{l}6 \\
5.08 \% \\
\end{array}$ & $\begin{array}{l}11 \\
4.91 \% \\
\end{array}$ & $\begin{array}{l}1 \\
1.75 \% \\
\end{array}$ & $\begin{array}{l}18 \\
4.16 \%\end{array}$ \\
\hline Posts & 33 & 118 & 224 & 57 & $432 / 100 \%$ \\
\hline
\end{tabular}

\section{References}

Bakhtin, M. (1984). Rabelais and His World. Transl. by Iswolsky, H. Bloomington: Indiana University Press.

Bergson, H. (2014). Laughter: An Essay on the Meaning of the Comic. Transl. by Brereton, C. \& Rothwell, F. Available online: www.templeofearth.com/ [Accessed on 4 June 2014].

Bogel, F. V. (2001). The Difference Satire Makes: Rhetoric and Reading from Byron to Jonson. New York: Cornell University Press. 
Cohen, S. (2002). Folk Devils and Moral Panics: The Creation of Mods and Rockers (3rd ed.). London and New York: Routledge.

Davies, C. (1998). Jokes and their Relation to Society. Berlin, New Yok: Mouton de Gruyter.

Davies, C. (2001). 'Humour is not a strategy in war'. Journal of European Studies 31: pp. 395412.

Davies, C. (2010). 'Jokes as the truth about Soviet socialism'. Folklore 146: pp. 9-34.

Davies, C. (2011). Jokes and Targets. Bloomington: Indiana University Press.

De Certeau, M. (1984). The Practice of Everyday Life. Berkeley: University of California Press. Draitser, E. (1998). 'Folk humor in post-Soviet Russia: A survey'. SEEFA Journal 3 (1): pp. 513.

Frye, N. (2000). Anatomy of Criticism (15th ed.). Princeton: Princeton University Press.

Gardiner, M. E. (2000). Critiques of Everyday Life. London, New York: Routledge.

Gray, J., Jeffrey, P. J. \& Ethan T. (eds.). (2009). Satire TV: Politics and Comedy in the PostNetwork Era. New York, London: New York University Press.

Griffin, D. H. (1994). Satire: A Critical Reintroduction. Lexington: University Press of Kentucky.

Hammoudi, A. (1997). Master and Disciple. Chicago: The University of Chicago Press.

Jenkins, H. (2006). Convergence Culture: Where Old and New Media Collide. New York: New York University Press.

Knight, C. (2004). The Literature of Satire. Cambridge: Cambridge University Press.,

Kuipers, G. (2008). 'The sociology of humor', in Raskin, V. (ed.), The Primer of Humor Research, Berlin, New York: Mouton de Gruyter, pp. 365-402.

Kuipers, G. (2011). 'The politics of humor in the public sphere: Cartoons, power and modernity in the first transnational humor scandal'. European Journal of Cultural Studies 14 (1): pp. 63-80.

Mansouri, N. (2013). The Sociology of the Internet (in Arabic). Beirut: Muntada Almaarif.

Milner, R. (2013). 'Hacking the social: Internet memes, identity antagonism, and the logic of lulz". The Fibre culture Journal 2: pp. 63-92.

Noelle-Neuman, E. (1974). 'The spiral of silence: A theory of public opinion'. Journal of Communication Spring: pp. 43-51.

Noelle-Neuman, E. (1991). 'The theory of public opinion: The concept of the spiral of silence', in Anderson, J. A. (ed.), Communication Yearbook, Newbury Park: Sage, pp. 256-287.

Oring, E. (2003). Engaging Humor. The Board of Trustees of the University of Illinois.

Quintero, R. (ed.). (2007). A Companion to Satire: Ancient to Modern. Malden: Blackwell Publishing.

Rose, M. A. (1993). Parody: Ancient, Modern, and Post-modern. Cambridge: Cambridge University Press.

Sater, J. N. (2007). Civil Society and Politcal Change in Morocco. London: Routledge.

Sater, J. N. (2010). Morocco: Challendes to Tradition and Modernity. London: Routledge.

Scott, J. C. (1990). Domination and the Arts of Resistance: Hidden Transcripts. Ann Arbor: Yale University Press.

Shehata, S. (1992). 'The politics of laughter: Nasser, Sadat, and Mubarek in Egyptian political jokes'. Folklore 103: pp. 75-91.

Shifman, L. (2012). 'An anatomy of a YouTube meme'. New Media and Society 14 (2): pp. 187-203.

Sperber, D. \& Wilson. D. (2012). ‘Explaining irony', in Meaning and Relevance, Cambridge: Cambridge University Press, pp. 123-145.

Waterbury, J. (1970). The Commander of the Faithful: The Moroccan Political Elite - A Study of Segmented Politics. New York: Columbia University Press. 
Zeghal, M. (2009). 'On the politic of sainthood: Resistance and mimicry in postcolonial Morocco'. Critical Inquiry 35 (spring): pp. 587-610. 